Available online on 15.05.2020 at http://jddtonline.info
Open Access to Pharmaceutical and Medical Research
unrestricted non-commercial use, provided the original work is properly cited

Open $\odot$ Access

Research Article

\title{
Utilization pattern of antibiotics and drug related problems in the orthopedic department at a tertiary care hospital: a prospective study
}

\author{
Dinesh Kumar Yadav1, Kadir Alam², Anil Kumar Sah³, Deependra Prasad Sarraf4* \\ ${ }_{1}^{1}$ Post-graduate student (M.Pharm.), Purbanchal University College of Medical and Allied Sciences, Morang, Nepal; Email: \\ phrdineshyadav@gmail.com \\ ${ }^{2}$ Associate Professor, Department of Clinical Pharmacology and Therapeutics, B.P. Koirala Institute of Health Sciences, Dharan, Nepal; Email: \\ kadir.alam@bpkihs.edu \\ ${ }^{3}$ Lecturer, Department of Pharmacy, Purbanchal University College of Medical and Allied Sciences, Morang, Nepal; Email: anilsah np@gmail.com \\ ${ }^{4}$ Associate Professor, Department of Clinical Pharmacology and Therapeutics, B.P. Koirala Institute of Health Sciences, Dharan, Nepal; Email: \\ deependraprasadsarraf@gmail.com
}

\begin{abstract}
Background: Antibiotics are generally prescribed for both prophylactically and to treat ongoing infections in the orthopedic department. Assessment of prescribing pattern at regular interval is essential to avoid inappropriate use of drugs.

Objectives: To know the utilization pattern of antibiotics and drug related problems like adverse drug reactions (ADR) and drug-drug interactions (DDI) in hospitalized patients.

Materials and Methods: A cross-sectional study was conducted among hospitalized patients using WHO Anatomical Therapeutic Chemical/Defined Daily Dose (ATC/DDD) methodology for one month duration in orthopedic department at a tertiary hospital. Standard data collection forms were used to collect the data. Descriptive statistics were used for analyzing the data.

Results: Out of 196, most of patients (72.96\%) were male and most of patients (34.69\%) were from the age group $21-30$ years. A total of 782 drugs were prescribed during study period and among them 262 were antibiotics. None of the drugs were prescribed in generic name. Ceftriaxone (33.58\%) was the most frequently prescribed antibiotic. Average cost of drug therapy per patient was NPR 3125.7. DDD/100 beddays were highest for Cefixime (27.9). A total of 233 ADRs were suspected in 64 patients (32.6\%). Thrombophlebitis (26.2\%) was the commonest ADR. Potential DDI were found in 51 patients (26.02\%). The most common interacting pairs were Cefuroxime and Rabeprazole (15 encounters).
\end{abstract}

Conclusion: Generic prescribing is urgently needed for cost minimization. The prevalence rate of ADR occurrence and DDI was high. The study finding benefits the hospital policy makers to formulate and address policies for rational use of antibiotics.

Keywords: Adverse Drug Reactions; Antibiotics; Cost; Drug Utilization; Drug-Drug interaction

Article Info: Received 08 March 2020; Review Completed 14 April 2020; Accepted 18 April 2020; Available online 15 May 2020

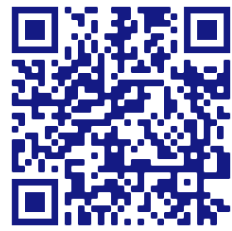

\section{Cite this article as:}

Yadav DK, Alam K, Sah AK, Sarraf DP, Utilization pattern of antibiotics and drug related problems in the orthopedic department at a tertiary care hospital: a prospective study, Journal of Drug Delivery and Therapeutics. 2020; 10(3):24-30 http://dx.doi.org/10.22270/jddt.v10i3.4056

\section{*Address for Correspondence:}

Dr. Deependra Prasad Sarraf, Associate Professor, Department of Clinical Pharmacology and Therapeutics, B.P. Koirala Institute of Health Sciences, Dharan, Nepal

\section{INTRODUCTION}

Drug therapy plays an important role in the management of diseases in hospitalized patients. Excessive and inappropriate drug therapy is associated with various negative consequences. ${ }^{1}$ Overuse of drugs, polypharmacy and the prescribing of inappropriate drugs is greater in lowand middle-income countries.2 Drug therapy accounts for up to $60 \%$ of total health care spending in low- and middle income countries. ${ }^{3}$ For every United States dollar spent on drug therapy, one additional dollar is needed to correct drug related problems caused by inappropriate use of drugs. ${ }^{4}$

ISSN: 2250-1177
Drug utilization research has a crucial role in clinical practice to facilitate rational use of drugs. It forms the basis of making amendments in the drug prescribing policies at hospitals. It also helps in developing strategies to utilize health resources in the most efficient manner.5,6 Periodic evaluation of utilization patterns of drugs is essential to identify the irrational and inappropriate use of drugs. ${ }^{7}$ It helps to maximize therapeutic benefits and minimize adverse effects, to suggest the prescriber for suitable modifications in the prescribing behavior for rational and cost-effective treatment and also provides feedback to the prescriber and 
creates awareness among them about rational use of drugs. ${ }^{8-}$

Antibiotics are one of the most commonly prescribed drugs for prophylaxis or to treat current infection in hospitalized patients in orthopedic departments. ${ }^{10}$ Unnecessary use of antibiotics is a major global problem. Appropriate use of antibiotics in hospitalized patients should ensure effective treatment but reduce unnecessary prescriptions whereas its inappropriate use may leads to adverse effects, development of resistance and increased the cost of therapy.11,12 As antibiotic consumption is one of the major driver force for resistance, its monitoring is a recommended component of antimicrobial stewardship programs. Despite of detailed research on utilization pattern of antibiotics in the hospitals in many countries, no sufficient data is available for our country. ${ }^{13}$ Data on drug-related problems in hospitalized patients are also scarce. Objectives of the study were to know the utilization pattern of antibiotics and drug related problems like adverse drug reactions (ADR) and drug-drug interactions (DDI) in hospitalized patients in the orthopedic ward.

\section{MATERIALS AND METHODS}

It was a cross-sectional study conducted among 196 hospitalized patients during September 2018 in Orthopedics ward at Koshi Zonal Hospital, Biratnagar, Nepal. The ward had 35 beds and bed occupancy rate was 0.81 . The hospitalized patients and prescribed with at least one antibiotics and aged 18 years and above were enrolled in the study. The patients not prescribed any medicine or attended the out-patient department or admitted in the other departments were excluded. The data were collected using two types of semi-structured proforma; encounter form for collecting sociodemographic data like age, gender, marital status, medical history, diagnosis, drugs prescribed (dose, frequency and route of administration, dosage form, duration of drug therapy) and ADR reporting form developed by the National Pharmacovigilance Center,
Department of Drug Administration, Nepal was used for the suspected ADR. ${ }^{14,15}$

The outcome variables were therapeutic group and numbers of drugs prescribed, therapeutic group and numbers of antibiotic used, prescription frequency of individual antibiotics, prescription frequency of class of antibiotics, average number of drugs and antibiotics per patient prescribed, classification of antibiotics, antibiotics consumption, cost of drug and antibiotic therapy, ADR and its causality assessment and DDI. The mean number of drugs prescribed per patient was computed by dividing the whole number of drugs prescribed to the number of patients. Naranjo algorithm scale was used to categorize ADR as Definite (score more than or equal to 9), Probable (score 58), Possible (score 1-4), Doubtful (score less than or equal to $0) .16$ Medscape drug interaction checker was used to identify DDI. ${ }^{17}$

Anatomical Therapeutic Chemical (ATC) classification system and Defined Daily Dose (DDD) were used to obtain antibiotic classification and consumption respectively. In the ATC classification, active chemical substances are classified in a hierarchy of five levels. The first level comprises 14 main anatomical/pharmacological groups, each of which is divided into pharmacological or therapeutic subgroups (second level). The third and fourth levels are chemical, pharmacological or therapeutic subgroups and the fifth level is the chemical substance. ${ }^{18}$ DDD is a unit of measurement of the assumed average maintenance dose per day for a drug used for its main indication in adults. The amount of DDD consumption was calculated separately for each antibiotic by dividing the total amount of consumption in grams by antimicrobial-specific average DDD as per of WHO. DDDs per 100 bed-days was used to estimate of consumption of antibiotics. DDD assigned by ATC/DDD index 2010 assigned by WHO Collaborating Center for Drug Statistics Methodology was used.18 DDDs per 100 bed-days was calculated using the following formula,

DDD $/ 100$ bed-days $=$

No. of units administered in the study period (mg)

$\mathrm{x} 100$

DDD (mg) * No. of days in study period * No. of beds * Bed occupancy

Cost of total drug therapy was measured by using the cost of the hospital pharmacy and expressed in Nepalese Rupees (NPR). The study was approved by Nepal Health Research Council (553/2018), Kathmandu, Nepal.

A pilot study was carried out for one week for validating the different data collecting forms. Necessary modification and correction on the data collection method and other assessment parts was done based on the results of the pilot study. The patients used in the pilot study were not included in the study. No incentive was given to the patients. Confidentiality of the patients was maintained.

The data were rechecked and entered into Microsoft Office Excel 2010. Continuous variables were presented as means, standard deviations and sums. Categorical variables were presented as frequencies and percentages. All statistical calculation were conducted using SPSS version 11.5.

\section{RESULTS}

Out of 196 patients, 143 (72.96\%) were male. The age ranged from 18 to 85 years with mean age of $36.64 \pm 14.64$ years. Most of patients (34.69\%) were from the age group 21-30 years followed by 31-40 years (26.02\%) (Table 1).
Table 1: Socio-demographic characteristics of patients (n=196)

\begin{tabular}{|l|c|}
\hline Characteristics & Number (\%) \\
\hline Age groups (years): & $20(10.20)$ \\
$18-20$ & $68(34.69)$ \\
$21-30$ & $51(26.02)$ \\
$31-40$ & $27(13.78)$ \\
$41-50$ & $13(6.63)$ \\
$51-60$ & $10(5.10)$ \\
$61-70$ & $7(3.57)$ \\
$>70$ & $143(72.96)$ \\
\hline Gender: & $53(27.04)$ \\
Male & $36.64 \pm 14.64$ \\
Female & \\
\hline Mean age $( \pm$ SD) & \\
\hline
\end{tabular}

Bone fracture $(20.9 \%)$ was the most common diagnosis of patient followed by cellulitis $(17.9 \%)$ and road traffic accident (14.3\%) (Table 2). 
Table 2: List of the diagnosis in the patients $(n=196)$

\begin{tabular}{|c|c|c|}
\hline Age groups (Years) & Number & Percentage \\
\hline Fracture & 69 & 35.2 \\
\hline Cellulitis & 35 & 17.9 \\
\hline Infected Wound & 24 & 12.2 \\
\hline Abscess & 18 & 9.2 \\
\hline Septic Arthritis & 14 & 7.1 \\
\hline Others & 13 & 6.6 \\
\hline Cut Injury & 12 & 6.1 \\
\hline
\end{tabular}

A total of 782 drugs were prescribed to 196 patients during the study period. Antibiotic (33.5\%) were the most common prescribed drugs followed by non-steroidal antiinflammatory drugs (32.1\%) and gastrointestinal drugs (20.84\%) (Table 3). Average number of drugs per patient and average number of antibiotics per patient were 3.99 and 1.34 respectively. None of the drugs were prescribed in generic name.
Table 3: List of the therapeutic categories of the prescribed drugs $(n=782)$

\begin{tabular}{|c|c|c|}
\hline $\begin{array}{c}\text { Therapeutic categories of } \\
\text { drugs }\end{array}$ & Number & Percentage \\
\hline Antibiotics & 262 & 33.50 \\
\hline $\begin{array}{c}\text { Non-steroidal anti- } \\
\text { inflammatory drugs }\end{array}$ & 251 & 32.10 \\
\hline Gastrointestinal & 163 & 20.84 \\
\hline Anti-inflammatory enzymes & 58 & 7.42 \\
\hline Others & 26 & 3.32 \\
\hline Opioid analgesics & 22 & 2.81 \\
\hline
\end{tabular}

During the study period, Cephalosporin (69.08\%) was the most frequently prescribed group of antibiotics followed by Nitroimidazoles (12.98\%). Ceftriaxone (33.58\%) was the most common antibiotic prescribed consisting of Ceftriaxone alone (71.59\%), Ceftriaxone + Sulbactam (22.27\%) and Ceftriaxone + Tazobactam (1.14\%) (Table 4).

Table 4: List of the antibiotics according to ATC classification $(n=262)$

\begin{tabular}{|l|c|c|c|}
\hline \multicolumn{1}{|c|}{ Categories of antibiotics } & ATC code & Number & Percentage \\
\hline 1. Cephalosporins: & & 181 & 69.08 \\
Ceftriaxone & J01DD04 & 88 & 48.62 \\
Cefuroxime Axetil & J01DC02 & 83 & 45.86 \\
Cefixime & J01DD08 & 8 & 4.42 \\
Cefoperazone & J01DD12 & 1 & 0.55 \\
Cefpodoxime Proxetil & J01DD13 & 1 & 0.55 \\
\hline 2. Nitroimidazoles: & & 34 & 12.98 \\
Metronidazole & J01XD01 & 33 & 97.06 \\
Ornidazole & J01XD03 & 1 & 2.94 \\
\hline 3. Aminoglycosides: & & 25 & 9.54 \\
Amikacin & J01GB06 & 18 & 72.00 \\
Tobramycin & J01GB01 & 7 & 28.00 \\
\hline 4. Lincosamide: Clindamycin & G01AA10 & 13 & 4.96 \\
\hline 5. Penicillins: & & 4 & 1.53 \\
Amoxicillin & J01CA04 & 1 & 25.0 \\
Ampicillin & J01CA01 & 3 & 75.0 \\
\hline 6. Oxazolidinone: Linezolid & J01XX08 & 3 & 1.15 \\
\hline 7. Fluoroquinolone: Ciprofloxacin & J01MA02 & 2 & 0.76 \\
\hline
\end{tabular}

Cost of the drug therapy ranged from 115 to 13283 Nepalese Rupees (NPR) per patient. Average cost of drug therapy per patient was NPR 3125.7. Cost of antibiotics ranged from
NPR 35 to 12750 . The average costs of antibiotics per patients was NPR 2432.5 (Table 5). 
Table 5: Cost of total drug therapy and antibiotic therapy $(n=196)$

\begin{tabular}{|c|c|c|c|c|}
\hline \multirow{2}{*}{ Cost (NPR) } & \multicolumn{2}{|c|}{ Total drug therapy } & \multicolumn{2}{c|}{ Antibiotics therapy } \\
\cline { 2 - 5 } & Number & Percentage & Number & Percentage \\
\hline $35-2000$ & 79 & 40.3 & 87 & 44.4 \\
\hline $2001-4000$ & 64 & 32.7 & 79 & 40.3 \\
\hline $40001-6000$ & 28 & 14.3 & 18 & 9.2 \\
\hline $6001-8000$ & 14 & 7.1 & 7 & 3.6 \\
\hline $80001-10000$ & 9 & 4.6 & 4 & 2.0 \\
\hline$>10000$ & 2 & 1.0 & 1 & 0.5 \\
\hline
\end{tabular}

Most of the patients (65\%) were prescribed one antibiotics (Figure 1).

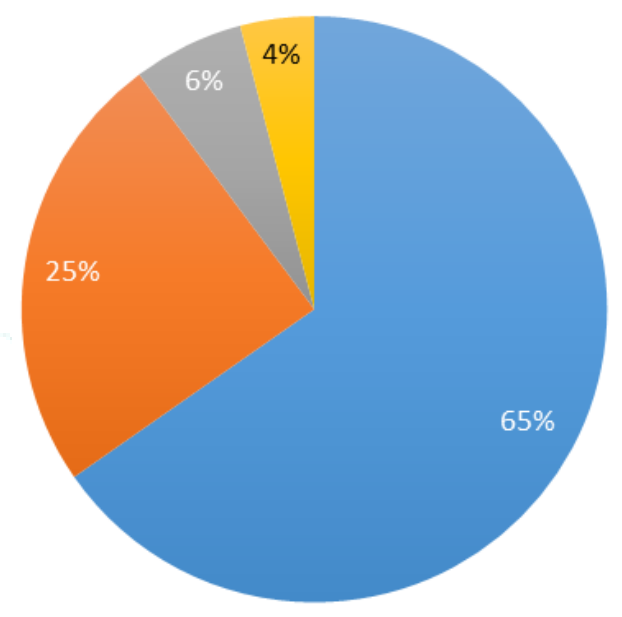

a 1 - 2 - $3>3$

Figure 1: Number of antibiotics per patients $(n=196)$

Consumption of antibiotic in the term of DDD/100 bed-days is given in the Table 6. DDD/100 bed-days was highest for Cefixime (27.19).

Table 6: Pattern of consumption of the antibiotics $(n=196)$

\begin{tabular}{|c|c|c|c|}
\hline Antibiotics & ATC Code & $\begin{array}{l}\text { DDD assigned by } \\
\text { WHO (g) }\end{array}$ & DDD/100 bed-days \\
\hline Cefixime & J01DD08 & 0.4 & 27.19 \\
\hline Ceftriaxone & J01DD04 & 2 & 22.40 \\
\hline Tobramycin & J01GB01 & 0.24 & 14.21 \\
\hline Metronidazole & J01XD01 & 1.5 & 12.63 \\
\hline Amikacin & J01GB06 & 1 & 10.85 \\
\hline Cefuroxime Axetil & J01DC02 & 3 & 10.40 \\
\hline Clindamycin & J01FF01 & 1.8 & 3.79 \\
\hline Cefpodoxime Proxetil & J01DD13 & 0.4 & 2.94 \\
\hline Ciprofloxacin & J01MA02 & 0.8 & 2.02 \\
\hline Linezolid & J01XX08 & 1.2 & 1.57 \\
\hline Ornidazole & J01XD03 & 1 & 0.71 \\
\hline Amoxicillin & J01CA04 & 1.5 & 0.21 \\
\hline Ampicillin & J01CA01 & 2 & 0.17 \\
\hline Cloxacillin & J01CF02 & 2 & 0.17 \\
\hline Cefoperazone & J01DD12 & 4 & 0.07 \\
\hline
\end{tabular}


A total of 233 ADR were suspected in 64 patients (32.6\%). Thrombophlebitis (26.2\%) was the commonest ADR followed by dry mouth (14.2\%) and nausea and vomiting
(13.3\%) (Figure 2). All ADRs were probable on causality assessment.

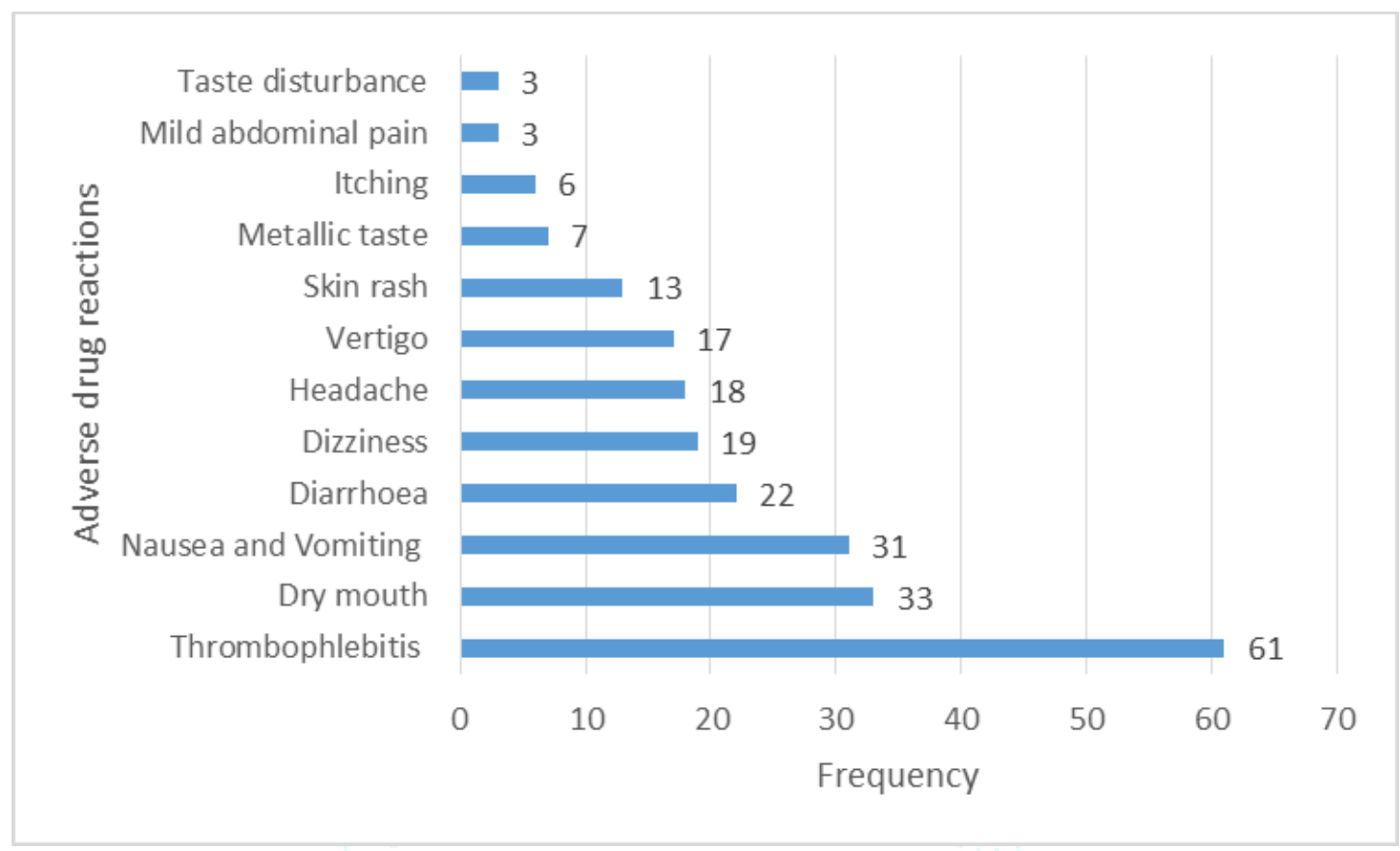

Figure 2: List of adverse drug reactions $(n=233)$

Potential DDI were found in 51 patients (26.02\%). A total of 51 interacting drug pairs were identified. Pharmacokinetic type of reactions $(45,88.2 \%)$ were found to be more common than pharmacodynamics type $(6,11.8 \%)$. Most of
DDIs were of minor severity (88.23\%). The most common interacting pairs was Cefuroxime and Rabeprazole (15 encounters). DDIs involving Cefuroxime $(24,47.1 \%)$ was the most common (Table 7).

Table 7: List of Potential drug-drug interactions $(n=51)$

\begin{tabular}{|l|c|c|l|}
\hline \multicolumn{1}{|c|}{ Drug Interaction } & $\begin{array}{c}\text { Number of } \\
\text { encounter } \mathbf{( s )}\end{array}$ & Severity & \multicolumn{1}{|c|}{ Effect due to interaction } \\
\hline Cefuroxime + Rabeprazole & 15 & Minor & Decreased absorption \\
\hline Ketorolac + Amikacin & 8 & Minor & Decreased renal clearance \\
\hline Cefuroxime + Omeprazole & 6 & Minor & Decreased absorption \\
\hline Ketorolac + Tobramycin & 5 & Minor & Decreased renal clearance \\
\hline Cefuroxime + Ranitidine & 2 & Minor & Decreased absorption \\
\hline Metronidazole + Diclofenac & 2 & Minor & Decreased metabolism \\
\hline Naproxen + Amikacin & 2 & Minor & Decreased renal clearance \\
\hline Aceclofenac + Diclofenac & 2 & Minor & Increased bleeding \\
\hline Cefuroxime + Pantoprazole & 1 & Moderate & Decreased absorption \\
\hline Ketorolac + Ibuprofen & 1 & Serious & Increased toxicity \\
\hline Ketorolac + Losartan & 1 & Minor & Increased toxicity \\
\hline Ketorolac + Diclofenac & 1 & Serious & Increased toxicity \\
\hline Ketorolac + Ciprofloxacin & 1 & Minor & Increased risk of CNS stimulation \\
\hline Naproxen + Ketorolac & 1 & Serious & Increased toxicity \\
\hline Naproxen + Ibuprofen & 1 & Serious & Increased toxicity \\
\hline Tobramycin + Ranitidine & 1 & Minor & Decreased renal clearance \\
\hline Ciprofloxacin + Diclofenac & 1 & Minor & Increased risk of CNS stimulation \\
\hline
\end{tabular}

\section{DISCUSSION}

Study of utilization of antibiotics can help to have bird's eye view regarding the present practice of prescribing antibiotics so that a timely intervention can help to promote rational pharmacotherapy. Assessment of drug related problems can help to develop policy to minimize the problems to maximize the therapeutic effect of drugs. Our study provides an insight into the utilization pattern of antibiotics and drug related problems in hospitalized patients at a tertiary center. Most of the patients were male in our study. Similar findings had been reported by Choudhary et al and Das et al.19,20 More 
than one third of the patients were from age group of 21-30 years. This finding was in accordance with the results of Das et al. ${ }^{20}$ Mean age of the patient was 36.64 years. In contrast to this finding, a higher mean age (44 year) was reported by Abhilash et al. ${ }^{21}$ Majority of the patient had bone fracture. Contrast to this, road traffic accident was the most common diagnosis in a study by Bithi et al. and Das et al.20,22

Antibiotic were the most commonly prescribed drugs in the study. Similar finding was also reported by a study from West Bengal, India in which antibiotics consisted of $31.17 \%$ of total drugs prescribed. ${ }^{23}$ Antibiotics must be used in case of bacterial infections and must be reserved for the future otherwise we may lose the most powerful tool to treat severe infections in future. None of the drugs were prescribed in generic name. Other study showed that percentage of drugs prescribed by generic names was $15 \%$ in Western Nepal and $87 \%$ in Thailand. 24,25 This is an issue of concern and can be readdressed to some extent by prescribers' education. Prescribing of antibiotics by the brand names may lead to increase risks of morbidity and mortality along with financial burdens on health care budgets. The WHO also recommends prescribing by generic names. ${ }^{26}$ Prescribing by generic name helps the hospital pharmacy to have a better inventory control. It can also reduce the confusion among the pharmacists while dispensing. Generic drugs are often more economic than the branded ones. ${ }^{24}$

Average number of drugs prescribed per patient was high (3.99) in the study. Similar findings were also reported by study from West Bengal, India in which average number average no of drugs per prescription was 3.4.23 In contrast, average number average number of drugs per prescription was 6.95 in an Indian study. ${ }^{27}$ Average number of antibiotics prescription were 1.34 and this was lower than 1.71 as reported by Ray et al.27 It is preferable to keep the number of drugs per prescription as low as possible since polypharmacy leads to increased risk of drug interactions, increased cost of drug therapy and medication-errors. Almost two third of the patients were prescribed one antibiotic only. A lower proportion of the patients were prescribed only one antibiotic in a study by Bithi et al. ${ }^{22}$ Only six percent of the patients were prescribed three antibiotics. In contrast to this, nine percent patients were prescribed three antibiotics in a study by Bithi et al. ${ }^{22}$ This could be expected since mixed infections is common in orthopedic department.

More than two third of the patients received Cephalosporin. Similar findings were observed in other studies.28,29 Cephalosporins have broad spectrum of activity, low toxicity and ease of administration. Ceftriaxone was the most commonly prescribed antibiotic in our study. Similar finding was also reported by Das et al and Bozkurt et al. ${ }^{20,30}$ In contrast to this finding, Meropenem was the most commonly prescribed drug in a study by Ray et al. ${ }^{27}$ Ceftriaxone has high antibacterial potency, wide spectrum of activity and low potential for toxicity. These differences can be correlated with hospital and patient features, antibiotic policies of the hospitals, physicians' preferences and with the differences in the educational and health systems. ${ }^{31}$ The policy and guidelines on antibiotic uses in the hospital should be implemented to rationalize the pharmacotherapy. ${ }^{32}$

Cost of drug therapy is the one of the key component of rational use of medicine as it determine the medication adherence. ${ }^{33,34}$ Average cost of drug therapy and antibiotic therapy per patient was NPR 3125.7 and NPR 2432.5 respectively. This value was higher compared to the findings of the Atif et al and lower compared to the findings of Nia et al. ${ }^{35,36}$ Antibiotics were the most frequently used drugs in the ward and hence would know that they constitute an important part of the total drug expenditure in the hospitalized patients. The financial resources are scarce and affordability of the patient is less in developing country like Nepal and hence implementation of rational use of medicine becomes more important. The cost of therapy can be reduced by choosing the equally effective and less costly drug and generic drugs. ${ }^{24}$

The ATC/DDD system is widely used standard method for measuring antibiotic consumption. DDD provides a fixed unit of measurement, independent of price, currencies, package size and strength. DDDs per 100 bed-days was used to estimate of consumption of antibiotics. Drug consumption in DDDs helps estimate of consumption and also allows comparison of trends in drug consumption. ${ }^{18}$ Cefixime and Ceftriaxone were the most consumed antibiotics in Orthopedic department at Koshi Hospital in the period. Similar findings were also reported by Caldeira et al. ${ }^{37}$ The consumption in DDD/100 bed-days of Ceftriaxone was 22.4 and this finding was much lower than 24.4 reported by Ray et al. $^{27}$ It is urgent to develop guideline for antibiotic in the hospital to guide prescribing and dispensing. Surveillance of antibiotic consumption allows the quantification of the selection pressure on microbial populations and serves as an outcome measure of antibiotic stewardship programs. ${ }^{38}$

Prevalence of ADR was $32.6 \%$ in our study. Thrombophlebitis was the commonest ADR followed by dry mouth and nausea and vomiting. All ADRs were probable on causality assessment. A lower prevalence of ADR was reported by Ramesh et al and Bhatta et al.39,40 High prevalence of ADR in our study might be due to the fact that most of the patients were on intravenous drug therapy. The ADR prolongs hospitalization and also has economic implications. Clinicians should be familiar with the most common side effects of the most frequently used antibiotics maximize the drug therapy. The prevalence of potential DDI were found to be $26.04 \%$. Among total of 51 interacting drug pairs, pharmacokinetic type of reactions were more common. The most common interacting pairs was Cefuroxime and Rabeprazole. DDIs involving Cefuroxime was the most common. It is essential to identify possible DDIs to minimize the loss of effectiveness and toxicity of drugs.

\section{LIMITATIONS}

Our study had some limitations. The study duration was short and sample size was also small. Since it was a single department and single-center study, the study findings could not be generalized to other departments and hospitals. The patients were not followed. Nevertheless, our study provides baseline information on antibiotic consumption in hospitalized patients in orthopedic department. Using the study findings can be used to plan and implement different interventions of an antimicrobial stewardship program to improve the current prescription practices of antibiotics, reduce cost of drug therapy and avoid ADRs.

\section{CONCLUSIONS}

The study showed that ceftriaxone was the most frequently prescribed antibiotics. Generic prescribing is urgently needed for cost minimization. The prevalence rate of ADR occurrence and DDI was high. The number of medicines per prescription should be kept in minimum. The study finding benefits the hospital policy makers to formulate and address policies for rational use of antibiotics. Continuous monitoring of antibiotic use will eventually results in optimizing antibiotic prescription and the implementation of national strategies to improve patient safety. Pharmacists 
should be appointed to develop and implement surveillance system in the hospital and to promote rational prescribing.

\section{ACKNOWLEDGMENT}

We would to like to thank our heartfelt gratitude to our Principal, H.O.D and Faculties of Pharmacy Department, Purbanchal University College of Medical and Allied Sciences for their invaluable support and guidance.

\section{CONFLICT OF INTEREST}

There was no conflict of interest among the authors.

\section{REFERENCES}

1. Drews J. Drug discovery: a historical perspective. Science (New York, NY). 2000; 287(5460):1960-4.

2. Le Grand A, Hogerzeil HV, Haaijer-Ruskamp FM. Intervention research in rational use of drugs: a review. Health Policy and Planning. 1999;14(2):89-102.

3. Cameron A, Ewen M, Ross-Degnan D, Ball D, Laing R. Medicine prices, availability, and affordability in 36 developing and middle-income countries: a secondary analysis. Lancet. 2009; 373(9659):240-9.

4. Sellers JA. Medicare drug benefit. American Journal of HealthSystem Pharmacy. 1999; 56(15):1503.

5. Wettermark B, Vlahovic-Palcevski V, Salvesen Blix H, Ronning M, Vander Stichele RH. Drug utilization research. In: Hartzema AG, Tilson HH, Chan KA, eds. Pharmacoepidemiology and Therapeutic Risk Management. Cincinnati, OH, Harvey Whitney Books, 2008

6. World Health Organization. Introduction to drug utilization research. Oslo: 2003.

7. Ahmed Md, Ali N, Rahman UZ, Khan M. A Study on prescribing pattern in the management of arthritis in the department of Orthopedics. Scholars Research Library. 2012;4(1)5-27.

8. Jayanthi MK, Sushma NV (2014). Drug utilization pattern and pharmacoeconomic study in paediatric dentistry at a tertiary hospital. Int J Pharm Pharm Sci; 6 (2): 70-72.).

9. Suman RK, Deshmukh YA, Ray I, Gore VS. Drug utilization studies in glaucoma patients at MGM Medical College and Hospital. Int J Sci Res. 2013; 7(2):433-435.

10. Abhijit K, Jain P, Upadhyaya P, Jain S. Antibiotic prescribing in various clinical departments in a tertiary care teaching hospital in northern India. J Clin Diagn Res. 2014; 8(5):HC09-11.

11. Abula T, Kedir M. The pattern of antibiotic usage in surgical inpatients of a teaching hospital, northwest Ethiopia. Ethiopian Journal of Health Development. 2004;18(1):9863.

12. Austin DJ, Kristinsson KG, Anderson RM. The relationship between the volume of antimicrobial consumption in human communities and the frequency of resistance. Proc Natl Acad Sci USA. 1999;96(3):1152-6.

13. Hosoglu S, Esen S, Ozturk R. The effect of a restriction policy on the antimicrobial consumption in Turkey: a country-wide study. Eur J Clin Pharmacol 2005, 61(10):727-31.

14. World Health Organization. How to investigate drug use in health facilities: selected drug use indicators. Geneva, 1993.

15. Pharmacovigilance. Department of Drug Administration, Ministry of Health and Population, Government of Nepal, Kathmandu, 2018. [Available http://www.dda.gov.np/content/pharmacovigilance]

16. Naranjo CA, Busto U, Sellers EM, Sandor P, Ruiz I, Roberts EA, et al. A method for estimating the probability of adverse drug reactions. Clin Pharmacol Ther. 1981; 30(2):239-45.

17. Drug interaction checker. Medscape, 2016. [Available at https://reference.medscape.com/drug-interactionchecker]

18. WHO Collaborating Centre for Drug Statistics Methodology, Guidelines for ATC classification and DDD assignment 2013. Oslo, 2016. [Available at https://www.whocc.no/filearchive/publications/1_2013guideli nes.pdf]

19. Choudhury DK, Bezbaruah BK. Prescribing pattern of analgesics in orthopedic in-patient department at tertiary care hospital in Guwahati, Assam, Northeast India. Indian J Pharmacol. 2016;48(4):377-81.

20. Das SK, Kurra V, Guttu P, A Quadri, Chowdary TN, B Valya et al. Antibiotic and Analgesic utilization review in an orthopedics in- patient department of a tertiary care teaching hospital in Hyderabad. Int J Pharm. 2016; 6(3):1-79.

21. Abhilash S, Rashmi R Rao, Sivaguha Yadunath. Assessment of prescribing pattern among orthopedic in-patients using who prescribing indicators. Asian J Pharm Clin Res. 2018; 11(12):505-9.

22. Bithi SS, Khan Rahman Minnazur MD, Khan AU. Drug utilization study in orthopaedic units: Antibiotics prescribed in hospital out-patients in Dhaka, Bangladesh. International Current Pharmaceutical Journal. 2014; 3(9):318-21.

23. Kumar GA, Kumar DC, Ajay K, Madhumita R. Drug utilization study on antibiotics use in an orthopaedics department of a tertiary care hospital in west Bengal. Journal of drug delivery and therapeutics. 2013; 3(2):98-103.

24. Alam K, Mishra P, Prabhu M, Shankar PR, Palaian S, Bhandari RB et al. A study on rational drug prescribing and dispensing in outpatients in a tertiary care teaching hospital of Western Nepal. Kathmandu Univ Med J (KUMJ). 2006; 4(4):436-43.

25. Aswapokee N, Vaithayapichet S, Heller RF. Pattern of antibiotic use in medical wards of a university hospital, Bangkok, Thailand. Review Infect Dis. 1990; 12(1):136-41.

26. Promoting rational use of medicines: core components. WHO policy perspectives on medicines, WHO, 2016, Geneva. [Available http://apps.who.int/medicinedocs/en/d/Jh3011e/

27. Ray D, Datta S. A study on antimicrobial agents utilization pattern using anatomical therapeutic chemical/daily defined dose system and adverse drug reaction pattern in the intensive care unit of a tertiary care teaching hospital in North Eastern state of India. Int J Basic Clin Pharmacol 2018; 7:1612-9.

28. Gowthami B, Spurthi T and Afreen S. Drug utilization evaluation of antibiotics in general medicine department of a tertiary care hospital. Int J Pharm Sci. 2016; 8(6): 302-304.

29. Khade AM, M Bashir MS, George S, Annaldesh S and Bansod KA. Prescription pattern of antimicrobial agents in a teaching hospital of South India. Int J basic Clin Pharmacol 2013; 2:567570.

30. Bozkurt F, Kaya S, Tekin R, Gulsun S, Deveci O, Dayan S et al. Analysis of antimicrobial consumption and cost in a teaching hospital. J Infect Public Health. 2014;7 (2):161-9.

31. Kuster SP, Ruef C, Ledergerber B, Hintermann A, Deplazes C, Neuber L. Quantitative antibiotic use in hospitals: comparison of measurements, literature review and recommendations for a standart of reporting. Infection. 2008; 36(6):549-59.

32. DP Sarraf, GP Rauniar, A Misra. Drug utilization pattern in four major wards of a tertiary hospital in eastern Nepal. Health Renaissance. 2015; 13(2):50-65.

33. Aurel O Iuga, Maura J McGuire. Adherence and health care costs. Risk Manag Healthc Policy. 2014; 7:35-44.

34. Kuruvilla A, George K, Rajaratnam A, John KR. Prescription patterns and cost analysis of drugs in a base hospital in South India. Natl Med J India. 1994; 7(4):167-8.

35. Atif M, Azeem M, Sagib A, Scahill S. Investigation of antimicrobial use at tertiary care Hospital in Southern Punjab WHO Methodology. Antimicrobial Resistance and Infection Control. 2017; 6:41.

36. Nia SS, Hiremath SRR, Prasad S. Assessment of Antimicrobial Use Pattern Using World Health Organization Prescribing Indicators at a Tertiary Hospital: A Prospective, Observational study. Journal of Applied Pharmaceutical Science. 2018; 8(6):132-8.

37. LF Caldeira, MN Burattini. Analysis of antimicrobials' consumption profile in a University Hospital of Western Paraná, Brazil. Brazilian Journal of Pharmaceutical Sciences. 2009; 45(2):295-302.

38. Smita Anand Tiwari, Ghongane Balasaheb Baburao. ATC/DDD Method to Assess the Injectable Antibiotics Utilization in a Tertiary Care Teaching General Hospital in India. IOSR Journal of Dental and Medical Sciences (IOSR-JDMS). 2017; 16(6):39-43.

39. Ramesh M, Pandit J, Parthasarathi G. Adverse drug reactions in a south Indian hospital--their severity and cost involved. Pharmacoepidemiol Drug Saf. 2003; 12(8):687-92.

40. Batta A, Madan N, Kalra BS, Arora S. Prescription Audit, Drug Utilization Pattern and Adverse Drug Reaction Monitoring in Outpatients of Orthopedics Department of Tertiary Care Teaching Hospital: A Pilot Study. MAMC J Med Sci. 2019; 5(2):77-82 